Beef Cattle Research - 2008

\title{
BLADE TENDERIZATION IN COMBINATION WITH INJECTION ENHANCEMENT CONTAINING AN ENZYME INCREASES TENDERNESS OF STRIP STEAKS FROM FED CULL COWS
}

\author{
S. Hutchison, J. A. Unruh, M. J. Daniel, M. C. Hunt, and J. J. Higgins ${ }^{1}$
}

\section{Introduction}

Cow meat is tougher than meat from young steers and heifers and typically has a less desirable, darker color. It is generally assumed that cow meat will need to be ground or have some form of post-mortem tenderization applied to be merchandized as a whole muscle product. Most cow steaks are fabricated by food service providers for their customers with different specifications for aging and post-mortem tenderization application. Aging, blade tenderization, and injection enhancement are commonly used on cow meat to increase tenderness. It is unknown if an extended aging period is needed in addition to a combination of tenderization and injection enhancement to improve tenderness. If shorter aging periods can be used without compromising tenderness, then aging costs would be greatly reduced. Our objective was to determine the effects of days of aging and an enhancement protocol on tenderness of strip loin steaks from fed cull cows.

\section{Experimental Procedures}

This study used strip loins from 31 cull cows fed a high-concentrate diet for 60 days. The strip loin from both the right and left sides were removed, vacuum packaged, and randomly assigned to 7 or 28 days of aging. Fol- lowing aging, the loins were divided in half, vacuum packaged, and frozen until further processing. Strip loin halves that were to be enhanced were subsequently thawed for 36 hours, blade tenderized using one pass through a blade tenderizer, and injected at $10 \%$ of their weight with a solution containing $0.35 \%$ phosphate, $0.5 \%$ salt, and $0.023 \%$ bromelin. After pumping, strip halves were allowed 5 minutes to drip before they were vacuum packaged and refrozen. Using a band saw, all strip halves were cut frozen into three 1-inchthick steaks. Steaks were randomly assigned for Warner-Bratzler shear force (WBSF), sensory panel, and further laboratory analysis.

Frozen steaks for WBSF were thawed overnight, weighed in the package, removed from the package, and re-weighed to determine package loss percentages. Vacuum package loss was calculated by $100 \times$ (thawed steak in package weight - thawed steak weight)/thawed steak in package weight. Steaks were cooked to an internal temperature of $158^{\circ} \mathrm{F}$, cooled for 30 minutes, and reweighed to determine cooking loss percentages. Cooking loss was calculated by $100 \times$ (thawed steak weight - cooked steak weight)/thawed steak weight. Steaks were chilled overnight, and six 0.5 -inch cores were removed and sheared once perpendicular to the direction of the muscle fibers using the

${ }^{1}$ Department of Statistics. 
WBSF attachment on the Instron Universal Testing Machine.

Sensory panel steaks were cooked to an internal temperature of $158^{\circ} \mathrm{F}$ and served warm to a trained sensory panel. Myofibrillar and overall tenderness, connective tissue amount, firmness, juiciness, beef flavor, and off flavor were scored on a scale of 1 to 8 with $1=$ extremely tough, abundant, extremely soft, dry, extremely bland, and none; and $8=$ extremely tender, none, extremely firm, extremely juicy, extremely intense, and none, respectively.

Warner-Bratzler Shear Force and moisture losses were analyzed as a split plot. Aging served as the whole plot in a completely randomized block with animal serving as the blocking factor and enhancement as the subplot. Sensory data were analyzed as a split plot in a randomized complete block design. Panel session was used as the block to account for the potential variation due to session.

\section{Results and Discussion}

Sensory panelists found steaks aged for 7 days were more juicy, had more detectable connective tissue (lower scores), and were firmer than steaks aged for 28 days (Table 1). Steaks aged for 7 days also tended to have more beef flavor than steaks aged 28 days. Steaks aged for 7 days were less tender and had lower $\mathrm{pH}$ values than steaks aged for 28 days. No differences were noted in vacuum package losses between steaks aged 7 or 28 days.

Enhanced and non-enhanced steaks had similar sensory panel juiciness scores and vacuum package moisture losses (Table 2). Sensory panelists found enhanced steaks to have less beef flavor (lower score), be less firm, and have less detectable connective tissue than non-enhanced steaks. Enhanced steaks were more tender according to WBSF values and had a higher $\mathrm{pH}$ than non-enhanced steaks.
Aging $\times$ enhancement interactions $(\mathrm{P}<0.05)$ were observed for sensory panel myofibrillar tenderness, overall tenderness, and off flavor scores and percentage of cooking loss (Table 3). After 7 days of aging, enhanced steaks had more myofibrillar tenderness than nonenhanced steaks. Enhanced steaks aged for 28 days had the most myofibrillar tenderness compared with the other three treatments. In addition, non-enhanced steaks aged 28 days had more myofibrillar tenderness than the non-enhanced steaks aged for 7 days. Enhancement of steaks resulted in the highest overall tenderness scores compared with nonenhanced steaks. However, non-enhanced steaks aged 28 days had higher overall tenderness scores than non-enhanced steaks aged for 7 days. Sensory panelists noted that enhanced steaks had more off-flavors than nonenhanced steaks. In addition, enhanced steaks aged for 7 days had more off-flavor than enhanced steaks aged for 28 days. Nonenhanced steaks had more cooking loss than enhanced steaks, and enhanced steaks aged for 7 days had less cooking loss than enhanced steaks aged for 28 days.

As expected, enhancement increased $\mathrm{pH}$ due to the enhancement solution. While vacuum package loss did not differ due to the enhancement, enhanced steaks had higher initial moisture due to water added in the enhancement process and retained a higher percentage of moisture during the cooking process. However, enhancement slightly reduced beef flavor intensity and increased off-flavors. Overall, enhancement improved tenderness as indicated by both a sensory panel and WBSF. Aging improved tenderness as indicated by WBSF, but the sensory panel indicated improved tenderness for the non-enhanced steaks only.

\section{Implications}

Aging cow strip loins for 28 days to achieve maximum tenderness is not necessary when a combination of injection enhancement 
containing an enzyme and blade tenderization are used. Shorter aging periods can be used without compromising tenderness, resulting in reduced costs associated with aging.

Table 1. Sensory Panel and Warner-Bratzler Shear Force (WBSF) Values for Strip Steaks Aged for 7 or 28 Days

\begin{tabular}{|c|c|c|c|c|}
\hline \multirow[b]{2}{*}{ Trait } & \multicolumn{2}{|c|}{ Aging Time } & \multirow[b]{2}{*}{ SE } & \multirow[b]{2}{*}{ P-value } \\
\hline & 7 days & 28 days & & \\
\hline Juiciness & 5.5 & 5.2 & 0.07 & 0.0002 \\
\hline Beef flavor & 5.1 & 5.0 & 0.04 & 0.06 \\
\hline Connective tissue & 6.3 & 6.7 & 0.07 & $<0.0001$ \\
\hline Firmness & 5.0 & 4.6 & 0.08 & 0.0004 \\
\hline WBSF, lb & 8.2 & 6.5 & 0.23 & $<0.0001$ \\
\hline Vacuum package loss, \% & 2.6 & 2.7 & 0.08 & 0.43 \\
\hline $\mathrm{pH}$ & 5.7 & 5.8 & 0.01 & $<0.0001$ \\
\hline
\end{tabular}

Connective tissue amount, firmness, juiciness, and beef flavor scale: 1 = abundant, extremely soft, dry, extremely bland; and 8 = none, extremely firm, extremely juicy, extremely intense, respectively. 
Table 2. Sensory Panel and Warner-Bratzler Shear Force (WBSF) Values for Enhanced and Non-enhanced Strip Steaks

\begin{tabular}{lcccc}
\hline \hline Trait & Non-enhanced & Enhanced & SE & P-value \\
\hline Juiciness & 5.4 & 5.3 & 0.07 & 0.10 \\
Beef flavor & 5.4 & 4.6 & 0.04 & $<0.0001$ \\
Connective tissue & 5.6 & 7.3 & 0.07 & $<0.0001$ \\
Firmness & 6.2 & 3.5 & 0.08 & $<0.0001$ \\
WBSF, lb & 10.4 & 4.2 & 0.23 & $<0.0001$ \\
Vacuum package loss, \% & 2.6 & 2.7 & 0.08 & 0.48 \\
pH & 5.7 & 5.9 & 0.01 & $<0.0001$ \\
\hline
\end{tabular}

Connective tissue amount, firmness, juiciness, and beef flavor scale: 1 = abundant, extremely soft, dry, extremely bland; and 8 = none, extremely firm, extremely juicy, extremely intense, respectively.

Table 3. Sensory Panel Mean Values for Enhanced and Non-enhanced Strip Steaks Aged for 7 or 28 Days

\begin{tabular}{lccccc}
\hline & \multicolumn{4}{c}{ Cow } \\
\cline { 2 - 5 } Trait & \multicolumn{2}{c}{ Non-enhanced } & \multicolumn{2}{c}{ Enhanced } \\
\hline Myofibrillar tenderness & 7 days & 28 days & 7 days & 28 days & SE \\
Overall tenderness & $4.2^{\mathrm{a}}$ & $4.9^{\mathrm{b}}$ & $7.3^{\mathrm{c}}$ & $7.6^{\mathrm{d}}$ & 0.11 \\
Off flavor & $4.4^{\mathrm{a}}$ & $5.0^{\mathrm{b}}$ & $7.6^{\mathrm{c}}$ & $7.6^{\mathrm{c}}$ & 0.15 \\
Cooking loss, \% & $6.9^{\mathrm{c}}$ & $6.6^{\mathrm{c}}$ & $5.7^{\mathrm{a}}$ & $5.9^{\mathrm{b}}$ & 0.07 \\
\hline
\end{tabular}

${ }^{\text {abcd } M e a n s ~ w i t h i n ~ a ~ r o w ~ w i t h o u t ~ a ~ c o m m o n ~ s u p e r s c r i p t ~ l e t t e r ~ d i f f e r ~}(\mathrm{P}<0.05)$.

Myofibrillar and overall tenderness, and off flavor scale: 1 = extremely tough, and extreme off flavor; and 8 = extremely tender, and none, respectively. 